\title{
DIFERENTES COMPOSIÇÕES DE SUBSTRATOS PARA ACLIMATIZAÇÃO DE CATTLEYA AURANTIACA PROPAGADAS IN VITRO
}

\author{
Isabela Cordeiro Guedes ${ }^{1}$ \\ Wesley Gomes dos Santos ${ }^{2}$ \\ Vinícius Faúla Aguiar ${ }^{3}$ \\ Adriana Carvalho Rodrigues ${ }^{4}$ \\ Guilherme Augusto Rodrigues de Sousa ${ }^{5}$ \\ Edio Vicente de Jesus ${ }^{6}$ \\ Simone Alves ${ }^{7}$ \\ Fernanda Lima Barroso ${ }^{8}$
}

Resumo: Foram utilizadas plântulas de Cattleya aurantiaca germinadas in vitro. As mudas foram mantidas em casa-de-vegetação, utilizando sombrite, com retenção de $70 \%$ do fluxo de radiação solar e cobertura plástica. Para a irrigação foram utilizados nebulizadores. O delineamento estatístico utilizado foi inteiramente casualizado, sendo foram quatro tratamentos constituídos de quatro repetições, testando-se quatro composições de substratos, sendo: T1- $100 \%$ de substrato comercial Forth, T2- 50\% substrato comercial Forth, 30\% de Bagaço de Cana de Açúcar, 10\% de carvão vegetal e 10\% de isopor; T3- 50\% substrato comercial Forth, 20\% Bagaço de Cana de Açúcar, 10\% de carvão vegetal e 20\% de isopor; T4$50 \%$ substrato comercial Forth, 10\% Bagaço de Cana de Açúcar, 10\% de carvão vegetal e 30\% de isopor. Houve efeito do substrato no número médio de folha, sendo este o tratamento T3, tendo média de 5,54 folhas, sendo este o mais recomendado.

Palavras-chave: Orquídea; Produção de mudas; Aclimatização.

\footnotetext{
${ }^{1}$ Graduanda em Agronomia/Instituto Federal de Minas Gerais, Brasil. E-mail: isabela.agronomia@yahoo.com.br. ${ }^{2}$ Graduando em Agronomia/Instituto Federal de Minas Gerais, Brasil. E-mail:wesleysantossje@hotmail.com. ${ }^{3}$ Graduando em Agronomia/Instituto Federal de Minas Gerais, Brasil. E-mail: vinicius.aguiar.agr@gmail.com. ${ }^{4}$ Graduanda em Agronomia/Instituto Federal de Minas Gerais, Brasil. E-mail: adrianacr.agro@gmail.com. ${ }^{5}$ Graduando em Agronomia/Instituto Federal de Minas Gerais, Brasil. E-mail:guilherme.rodriguess@yahoo.com. ${ }^{6}$ Graduando em Agronomia/Instituto Federal de Minas Gerais, Brasil. E-mail: edio.jesus@outlook.com.

${ }^{7}$ Graduanda em Agronomia/Instituto Federal de Minas Gerais, Brasil. E-mail: simonealves_celeste@hotmail.com.

${ }^{8}$ Mestre em Fitotecnia /Instituto Federal de Minas Gerais, Brasil. E-mail: fernandalbarroso@gmail.com.
} 